\title{
Karakterer kan ikke erstatte jevnlige tilbakemeldinger
}

\author{
På medisinstudiet går det en debatt om gjeninnføringen av graderte karakterer. I Oslo vedtok fakultetsledel- \\ sen i 2013 at det skulle innføres en karakterskala fra A til F senest i 2017.
}

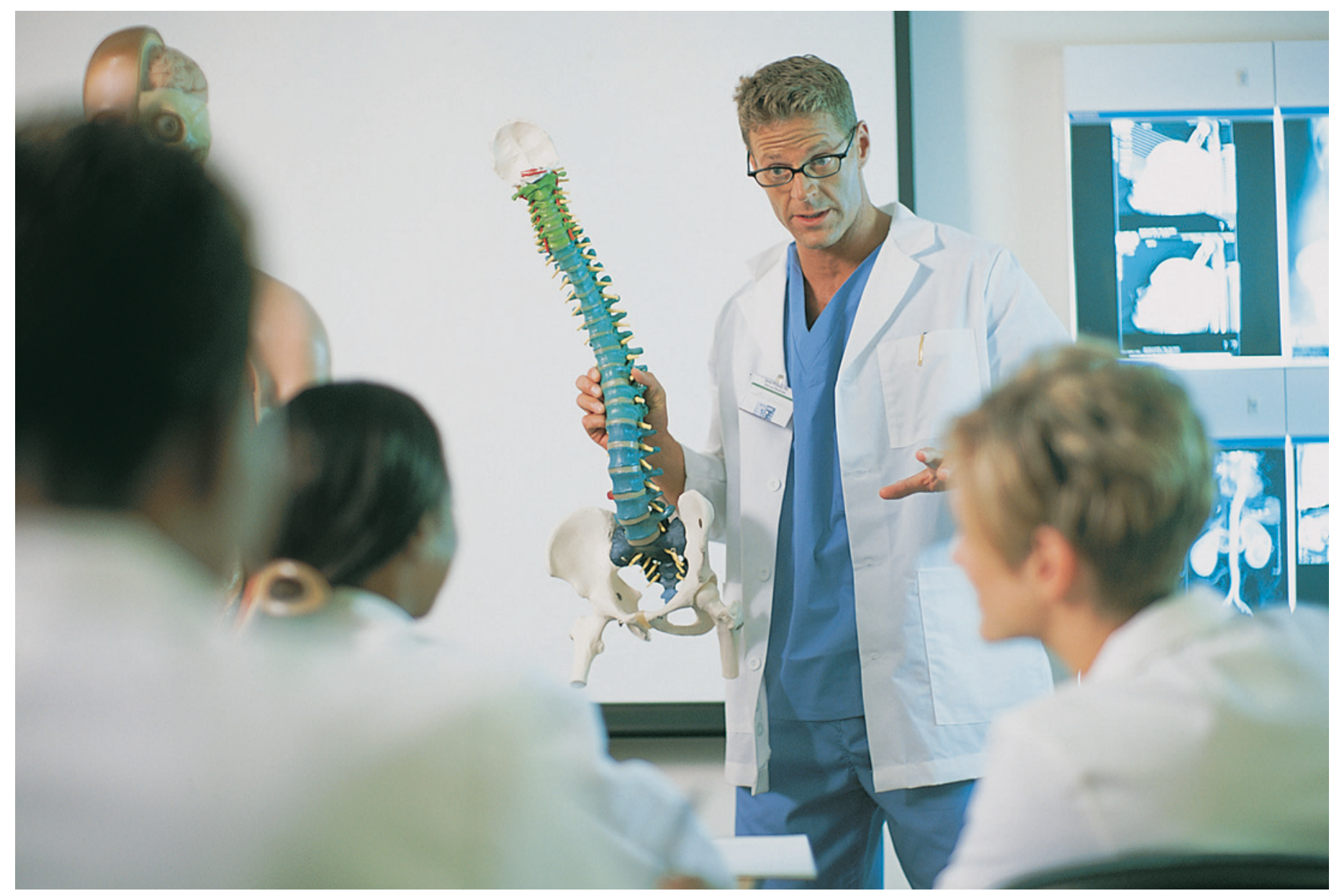

Karaktersystemet er en metode for formell vurdering som innenfor pedagogikken baserer seg på en såkalt behavioristisk tilnærming, der sterke prestasjoner belønnes med gode karakterer og svake prestasjoner straffes med lavere karakterer. Men hva gjør denne vurderingsformen med andre former for tilbakemeldinger som kan være vel så nyttige, for eksempel tilbakemeldinger underveis i læresituasjoner eller i etterkant av læresituasjoner?

I en nylig publisert studie undersøkte forskere hvordan ulike former for tilbakemelding i medisinske læresituasjoner kunne fremme mestring hos studentene (1). Forskerne gjennomførte seks kvalitative fokusgruppeintervjuer ved tre forskjellige medisinske fakulteter. Målet var å identifisere hvilke faktorer ved ulike vurderingssystemer på medisinstudiet som hindrer eller bedrer studentenes mottakelighet for feedback. Studien viste at studentens mulighet for å dra nytte av tilbakemelding ble større hvis tilbakemeldingen ble opplevd som ekte og relevant, og at studenten fikk passe mye støtte til å kunne tolke tilbakemeldingen på en konstruktiv måte.

Karakterer kan gi studenter en ekstern vurdering av egen prestasjon og nivå i forhold til andre. For noen av de som ble intervjuet var dette viktigst i starten av studiet. Men når man skal evalueres på samarbeid med pasienter, kolleger og annet personale, er andre former for tilbakemeldinger vel så viktige.

I studien konkluderer man med at uansett hvilke strukturer eller prinsipper som ligger til grunn for å vurdere faglige eller praktiske prestasjoner, burde disse gjøres så autentiske/ekte som mulig. Studien viser også at det er nyttig å gi langsiktig veiledning som støtter og utfordrer studentene passe mye, underveis i læreprosessen.

Dette innebærer at fordelene og ulempene med karaktersetting og andre former for evaluering bør vurderes. Karaktersystemet må tilpasses på en hensiktsmessig måte, både gjennom den teoretiske og praktiske delen av medisinstudiet, og bør kombineres med jevnlige tilbakemeldinger underveis.

\section{Cecilie N. Birkeli}

LEFO - Legeforskningsinstituttet

\section{Litteratur}

1. Harrison CJ, Könings KD, Dannefer EF et al. Factors influencing students' receptivity to formative feedback emerging from different assessment cultures. Perspect Med Educ 2016; 5: 276-84. 